\title{
Cooperation and conflict in the evolution of multicellularity
}

\author{
RICHARD E. MICHOD* \& DENIS ROZE \\ Department of Ecology and Evolutionary Biology, University of Arizona, Tucson, AZ 85721, U.S.A.
}

\begin{abstract}
Multicellular organisms probably originated as groups of cells formed in several ways, including cell proliferation from a group of founder cells and aggregation. Cooperation among cells benefits the group, but may be costly (altruistic) or beneficial (synergistic) to individual cooperating cells. In this paper, we study conflict mediation, the process by which genetic modifiers evolve that enhance cooperation by altering the parameters of development or rules of formation of cell groups. We are particularly interested in the conditions under which these modifiers lead to a new higher-level unit of selection with increased cooperation among group members and heritable variation in fitness at the group level. By sculpting the fitness variation and opportunity for selection at the two levels, conflict modifiers
\end{abstract}

\section{Introduction}

Evolutionary individuals are units of selection and must satisfy Darwin's conditions of heritability and variation in fitness. A theory for the origin of a new higher-level individual, such as the evolutionary transition from single cell to multicellular organisms, must explain how Darwin's properties emerge at the new level, out of the population biology of interacting lower level units. Although we believe a general set of principles guide the evolution of new individuals, to help fix ideas, we consider the following scenario for the origin of multicellularity (Fig. 1). Other scenarios are possible, although they also lead to the same set of general issues.

We assume that the single-celled ancestors of multicellular life were motile and able to alternate between reproductive and motile states (Margulis, 1981, 1993; Buss, 1987; Maynard Smith \& Szathmáry, 1995). We assume that there was a trade off between cell division and motility, such that dividing cells were less likely to be motile, and motile cells were less likely to divide. This constraint might have been related to the existence of a finite number of microtubule organizing centres per cell (Margulis, 1981, 1993; Buss, 1987) and/or to the existence of a cell wall (Kirk, 1997). The trade-off between motility and reproduction exists in several protist groups, such as choanoflagellates (thought to be the direct ancestors of the sponges), although many other protist groups, such as wall-less green flagellates, have solved this constraint and can reproduced

\footnotetext{
*Correspondence. E-mail: michod@u.arizona.edu
}

create new functions at the organism level. An organism is more than a group of cooperating cells related by common descent; organisms require adaptations that regulate conflict within. Otherwise their continued evolution is frustrated by the creation of within-organism variation and conflict between levels of selection. The evolution of conflict modifiers is a necessary prerequisite to the emergence of individuality and the continued well being of the organism. Conflict leads - through the evolution of adaptations that reduce it - to greater individuality and harmony for the organism.

Keywords: altruism, apoptosis, cooperation, germ line, group selection, levels of selection, mutation. while motile (Kirk, 1997). Nevertheless, Margulis and Buss argue that modern metazoans inherited this constraint between cell division and motility (Margulis, 1981; Buss, 1987). Motile cells divide more slowly in extant multicellular organisms like Pleodorina in the Volvocales (Bell \& Koufopanou, 1991) or the sponge Leucosolenia (Buss, 1987). Finally, we assume that the many advantages of larger size - like avoid predation (Boraas et al., 1998) or better homeostasis (Bell, 1985) — would favour single cells coming together or remaining together after cell division so as to form cell groups. Group formation could have been accomplished through the evolution of cell functions that promote group behaviour, for example, a cell adhesion molecule, structures that hold cells together in a group (e.g. collar structures in sponges), or a modification that impedes separation of cells after division (e.g. cytoplasmic bridges in some volvocalean green algae). It is at this point that our investigations begin.

If and when single cells began forming groups, motility would be altruistic, that is, costly to the cell (because the cell would divide more slowly), but beneficial for the group (assuming it was advantageous for groups to be able to move). Reduced motility by loss of the flagella is then a form of defection, as it allows greater reproductive capacity at the cell level (favoured by within-group selection). But, the loss of motility will be disadvantageous at the group level. According to this scenario, we are led to consider the fate of cooperation and defection in a multilevel selection setting during the initial phases of the transition from unicellular to multicellular organisms. 


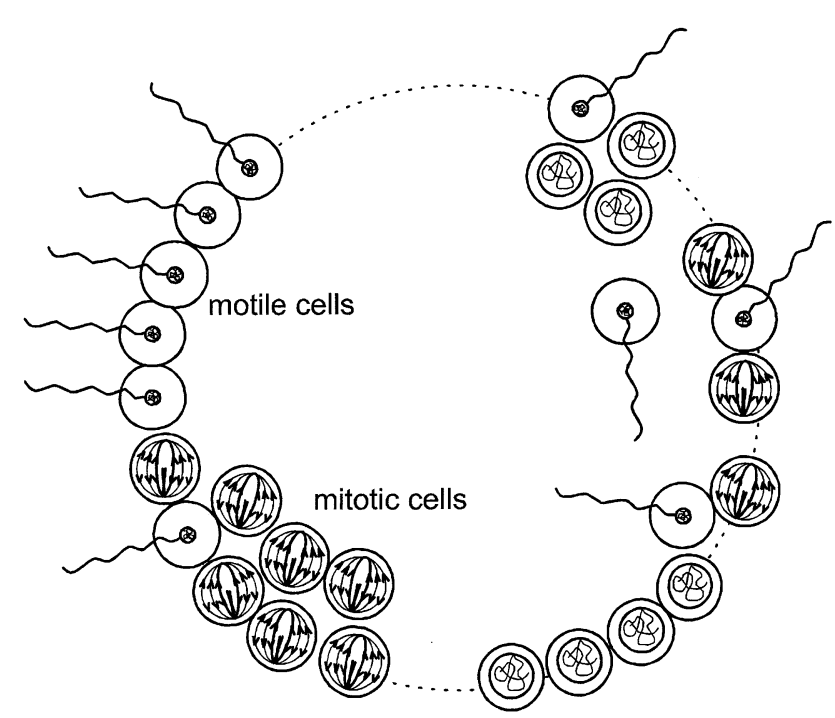

Fig. 1 Scenario for the first multicellular organisms (groups of cells). Shown in the figure are motile cells with a flagellum and non-motile mitotically dividing cells. It is assumed that cells cannot be motile and divide at the same time. As explained in the accompanying text, motile cells are an example of cooperating cells and mitotically reproducing cells are an example of defecting or selfish cells.

The example given in Fig. 1 generalizes in interesting ways to other evolutionary transitions, in which pre-existing traits with antagonistic pleiotropic effects on fitness at the lower level provide the basis for group beneficial traits. Life history evolution is replete with examples of traits with antagonistic pleiotropic effects on fitness, traits that increase one component of fitness while decreasing another. For example, allocation of energy to reproduction often decreases survivorship. For the colonial group in Fig. 1, cell motility detracts from cell reproduction and vice versa. For solitary organisms, individual selection balances these conflicting demands. However, what happens when the once solitary organism lives in a group and the benefits of these pleiotropic traits also act at a group level? Group selection may shift the trait away from the individual optimal state to one that is more beneficial to the group, even if this is costly to the individual. That is a possibility with the scenario assumed here, and it is also thought to occur during other evolutionary transitions, such as in the origin of eusociality in insects, in which group level traits such as division of labour can emerge from the existing variance in behaviours among organisms (Fewell \& Page, 1999).

\section{Theoretical framework}

We take a multi-level selection approach to evolutionary transitions, fitness variation and heritability. This approach has proved successful in understanding other transitions, such as the origin of sociality and the origin of cooperative gene networks. The basic problem in creating new evolutionary individuals involves generating heritable variation in fitness at the group level, while reducing the variation in fitness and scope for evolutionary change within groups. The group must become an individual: how can this occur?

Variation in fitness depends upon many processes and factors, including reproductive mode (e.g. asexual, sexual, fragmentation), reproductive specialization of group members (e.g. germ vs. soma in multicellular organisms or reproductive and worker castes in social insects), development and mutation. Understanding how these factors were shaped during the transition to multicellularity is a major concern of our work in this area (Michod, 1996, 1997, 1999; Michod \& Roze, 1997, 1999; Roze \& Michod, 2000).

\section{Cooperation}

We assume that the transition to multicellularity was fuelled by the benefits of cooperation and the advantages of large size. Cooperation is fundamental to the emergence of new levels of fitness in the biological hierarchy, because cooperation increases the fitness of the group, and new units of selection start out as groups of previously existing units. Thirty years ago, the study of cooperation received far less attention than other forms of ecological interaction (competition, predation and parasitism). What began as the study of animal social behaviour (Wilson, 1975), has now embraced the study of interactions at all biological levels. Cooperation is now seen as a primary creative force behind greater levels of complexity and organization in biology (Michod, 1999) and human culture (Wright, 2000). This is not to say that cooperation is the only force leading to higher-level units. Indeed, concerning another evolutionary transition - that of the origin of the eukaryotic cell - numerous evolutionary scenarios have been proposed and they involve almost every form of ecological interaction, from exploitative predator-prey (Sagan, 1967; Cavalier-Smith, 1987; Guerrero, 1991) or parasitic/pathogen (Blackstone, 1995; Kroemer, 1997) type interactions, to commensalistic (Margulis, 1981; Blackstone, 1995; Martin \& Müller, 1998; Blackstone \& Green, 1999) and mutualistic (Blackstone, 1995; Moreira \& Lopez-Garcia, 1998; Blackstone \& Green, 1999; Lopez-Garcia \& Moreira, 1999) interactions.

While it may be easy to agree on the basic role played by cooperation in the diversification of life, cooperation remains a difficult interaction to understand and model. When there is just one kind of cooperator (a single cooperative genotype), the cooperators must belong to the same species; when there is more than one kind of cooperator, the cooperators may belong to the same or different species. The study of cooperation has traditionally been divided by the issue of whether the interactions occur within or between species, however, both situations require spatial and or temporal correlations in the behaviour of cooperating individuals. That is to say there must be structure in the distribution of behaviours (Michod \& Sanderson, 1985). In the case of within-species interactions, genetic structure may facilitate behavioural structure as in kin selection. Because of the need for behavioural structure, competition may also occur among members of cooperative groups and this may reduce the advantages of cooperation (Taylor, 1992) or lead to the loss of cooperative types as in 
viscous populations (Queller, 1994). In the hypercycle, competitive exclusion of cooperative types is overcome by their cooperative interactions (Eigen \& Schuster, 1979; Frank, 1995, 1997). Although the cooperative interactions make it ecologically stable, the hypercycle is evolutionarily unstable, without some kind of group structure, because of the problem of selfish mutants (Maynard Smith, 1979; Michod, 1983, 1999; Boerlijst \& Hogeweg, 1991; Grey et al., 1995).

The number of different kinds of cooperators also affects how cooperation is modelled. When there is just a single kind of cooperator, game theoretic payoff matrices are often used to conceptualize the interaction, as in the well-studied Prisoner's dilemma game. The payoff matrix approach can be extended to interactions between two species (Law, 1991). When there are multiple members involved in the interaction, different approaches are used such as the hypercycle model (Eigen \& Schuster, 1979; Frank, 1995) or stochastic corrector model (Grey et al., 1995).

Another major issue in the study of cooperation concerns the nature of the benefits bestowed by cooperators. A fundamental question is whether cheating (obtaining the benefits of cooperation without paying the costs) is possible. Synergism occurs when benefits received from cooperation require the recipient to participate in the interaction. In other words, it is not possible for an individual to receive the (synergistic) benefits of cooperative acts of others without itself cooperating; defection or cheating is either disadvantageous or not possible.

Some of the scenarios for the origin of the eukaryotic cell assume that cooperation is synergistic (Lopez-Garcia \& Moreira, 1999). Synergism requires non-linearities in the contribution to fitness of each partner's behaviour. If we let the variables $X$ and $Y$ be the cooperative propensity of each partner, under an additive model of cooperation, fitness of each partner would be a linear function of these propensities. Cheating is possible for linear models, because one individual could have zero propensity to cooperate but still benefit from the cooperative acts of its partner. Synergism requires nonlinear fitness functions. For example, if we wanted there to be no benefits unless both partners cooperated, we might let each partner gain in proportion to the product of the cooperative propensities. If one partner did not cooperate, neither would receive any benefits. Other more realistic functions are possible, of course, however, our main point is that synergism requires nonlinear fitness effects of the interaction.

A problem with synergism alone as a scenario for the origin of cooperation is that it has difficulty explaining how cooperation gets started in a population of non-cooperators. If there is one kind of cooperator, say $C$, interacting with defectors, $D$, we may model the interaction in terms of the familiar payoff matrix given in Table 1 .

If $a>c$, we say there is synergism (Maynard Smith, 1998), cooperation is stable, and cheating is not possible when cooperation is established in the population. However, even in this case $(a>c)$, if cooperators pay a cost when their partner is not cooperating $(b<d)$ cooperation cannot invade when rare because cooperators interact predominately with defectors. One way around this problem is to assume that
Table 1 Payoff matrix for interactions between cooperators $(C)$ and defectors $(D)$. Parameters $a, b, c$ and $d$ give the fitness of the strategy on the left when interacting with the strategy on the top

\begin{tabular}{lll}
\hline & $C$ & $D$ \\
\hline$C$ & $a$ & $b$ \\
$D$ & $c$ & $d$ \\
\hline
\end{tabular}

cooperation is neutral when associated with defection, $b=d$. Explaining the origin of cooperation is a special virtue of kin selection. Kinship among individuals provides the requisite behavioural structure locally (say, within families), and cooperation can increase (because cooperators tend to be concentrated in certain families) even though cooperators are rare in the global population.

Another important issue in understanding cooperation is whether the benefits contributed by different cooperators are similar or different in kind (Queller, 1997). Sharing food is an example where the cooperating members provide similar benefits that are of the same kind and hence exchangeable. In contrast, role specialization in the castes of a termite colony, or cell and tissue specialization in a multicellular organism are both situations where the cooperators provide different kinds of benefits and one kind of benefit cannot be exchanged for another. The specialization of reproductive function into germ cells (and the creation of somatic cells) is another example of non-exchangeable benefits. The distinction made by Maynard Smith \& Szathmáry (1995) between rowing and sculling games expresses a similar issue. In rowing games, the oarsmen row on different sides of the boat (and so provide different and non-exchangeable functions). In sculling games, each oarsmen rows on both sides simultaneously (and so provides similar and exchangeable functions). The distinction is important, because cheating is much more costly in rowing games than in sculling games. In both kinds of games, the cooperators are in the same boat, which is another way of representing spatial and temporal correlations, that is behavioural structure.

Synergism may occur between functionally similar (sharing food, rowing games) or dissimilar members (sculling games, interspecies mutualisms). Synergism among functionally similar members must come from the economics of scale (Queller, 1997). Alliances of similar members must draw their (synergistic) benefits from the numbers of these members, in other words from scale. For example, larger colonies may be more buffered from environmental disturbances (Bell, 1985) or less likely to be eaten (Boraas et al., 1998), and these may be some of the advantages to forming early groups as in Fig. 1.

\section{Multi-level selection and mutation}

We wish to understand how fitness emerges at a new higher level out of the frequency-dependent interactions of lower level units. It is well know that frequency-dependent selection does not usually increase the fitness of the group (Wright, 1969), so 
Table 2 Effect of cell behaviour on fitness at the cell and organism level. The notation $+/-$ means positive or negative effects on fitness

\begin{tabular}{lcc}
\hline \multirow{2}{*}{$\begin{array}{l}\text { Cell } \\
\text { behaviour }\end{array}$} & \multicolumn{2}{c}{ Cevel of selection } \\
\cline { 2 - 3 } Defection & $\begin{array}{c}(+) \text { Replicate faster } \\
\text { or survive better }\end{array}$ & (-) less functional \\
Cooperation & $\begin{array}{c}(-) \text { replicate slowly } \\
\text { or survive worse }\end{array}$ & $\begin{array}{c}(+) \text { more } \\
\text { functional }\end{array}$ \\
\hline
\end{tabular}

how is it that group fitness may increase in magnitude and heritability? Cooperation creates new levels of fitness by increasing the fitness of the group, and, if costly at the lower level, by trading fitness from the lower level (the costs of cooperation to group members) to the higher level (the benefits to the group) (Michod, 1999). In Table 2, we illustrate this for the case of the transition between independent cells and multicellular organisms. Just as cooperation creates new levels of fitness, it creates the opportunity for conflict between levels as deleterious mutants arise and spread.

We assume that cell groups start out as offspring groups composed of $N$ cells (Michod \& Roze, 1999, 2000; Roze \& Michod, 2000). During development, cells proliferate and die (possibly at different rates depending on cell behaviour) to create the adult cell group. This produces offspring groups of the next generation, either by producing propagules or by direct fragmentation (Fig. 2). Deleterious mutation may occur during cell division leading to the loss of cooperative cell functions (such as the propensity to become motile in Fig. 1) and a decrease in fitness of the group.

We have studied two different kinds of cooperation, depending upon whether the cooperative phenotype is costly or beneficial at the cell level. When costly, cooperation is assumed to lower the cell's replication or survival rate. When beneficial, cooperation benefits the cell as well as the adult group, and so cooperation is synergistic. If we imagine offspring groups of two players (pair-wise encounters of $C$ cells and mutant $D$ cells) and assume that the elements of the payoff matrix in Table 1 represent the adult organism fitnesses after development, groups starting from $C C$ cells are always fitter as adults than groups starting from $C D$ cells $(a>c$ in Table 1). Costly forms of cooperation may also be synergistic, depending on the magnitude of the costs and other parameters.

Adult group fitness is assumed to increase with group size and functionality, and group functionality increases with the frequency of cooperative cells. The affect of mutation on group size depends on whether mutant cells replicate faster (selfish) or slower (uniformly deleterious) than non-mutant cells. Mutant cells, by virtue of not displaying the cooperative phenotype, decrease the functionality of the group. We believe that both kinds of mutations, selfish and uniformly deleterious, are important for understanding the evolution of cooperation and fitness heritability during the origin of multicellularity. We have studied such mutations using a variety of deterministic and stochastic techniques that allow (a) Fragmentation
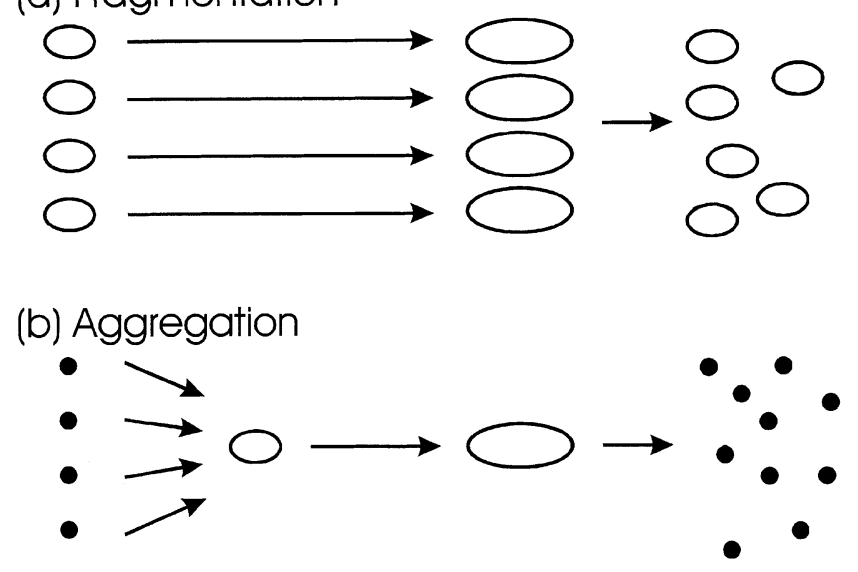

(c) Zygote or Spore

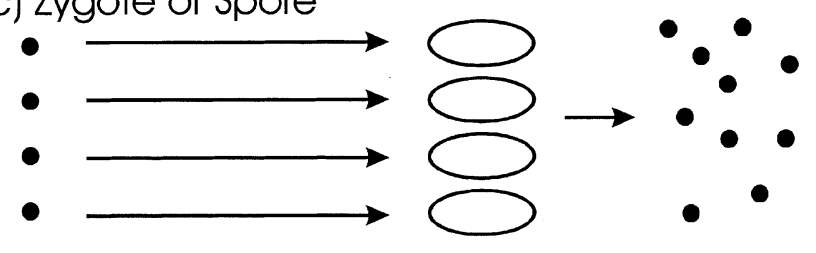

Fig. 2 Modes of reproduction. Small solid circles indicate single cells. Hollow ellipses indicate groups of cells. Small and large groups are shown. The small ellipses (of size $N$ in the model) correspond to offspring cell groups before cell division and development. The large ellipses correspond to adult groups. Under fragmentation (panel (a)), small offspring groups grow into larger adult cell groups, which produce offspring groups of the next generation. Under aggregation (panel (b)), single cells aggregate to form an offspring group which grows into an adult group which produce single cells of the next generation. Under zygote or spore reproduction (panel (c)), single cells divide and grow into adult cell groups which produce single cells of the next generation. If there is sex, fusion among single cells may occur in (c) prior to development into the multicellular form.

us to study a distribution of mutational effects (from uniformly deleterious to selfish) (Roze \& Michod, 2000; Michod \& Roze, 2000). In general, we have found that even a small proportion of selfish mutations (that is, most mutations being uniformly deleterious with a small fraction of selfish mutations) has significant effects on the evolution of genetic modifiers of the life cycle that change heritable fitness variation at the two levels.

\section{Reproductive mode}

Figure 2 presents three basic modes of reproduction that we have considered: fragmentation, aggregation and spore or zygote reproduction. In all three cases, the sequence of life cycle events involve the creation of a founding propagule or offspring group of cells of size $N$. This offspring group could be a single cell if $N=1$, as in the case of spore or zygote reproduction. Indeed the case of spore reproduction can be 
seen as the limiting case of both fragmentation and aggregation modes (by setting $N=1$ ). We have also considered the case of alternating fragmentation and spore reproduction every $v$ generations (Michod \& Roze, 1999). A fundamental difference between aggregation and the other reproductive modes is the opportunity for horizontal transfer of mutants to cell groups that contain no mutant cells. This is important because aggregation continually re-establishes mixed groups and concomitantly the opportunity for within-group selection and conflict between the two levels of selection.

Propagule size, $N$, influences fitness in several ways. First, propagule size affects the within- and between-group variance and opportunity for selection at the two levels. Smaller $N$ increases the between-group variance and decreases the withingroup variance. Second, propagule size has direct effects on fitness, because smaller $N$ increases the number of possible fragments, but decreases adult size. We find that the direct effects of propagule size dominate the indirect effects in the evolution of reproductive mode, except when some mutations are selfish, in which case the opportunity for selection at the two levels becomes the critical factor affecting the evolution of $N$.

\section{Conflict mediation}

We wish to understand how heritability of fitness, the defining characteristic of a unit of selection, may increase at the group level, so that the group may become an evolutionary individual. To continually adapt to its environment, an evolutionary individual must have mechanisms and features, such as a germ line or self-policing functions, which mediate conflict and reduce the opportunity for within-group change. These features shape development and the options of cells, thereby restricting the evolutionary potential of cells in favour of the group and, in so doing, make the group indivisible, that is, an individual.

Using the multilevel selection framework outlined above, we have estimated the levels of cooperation maintained in cell groups under various models of mutation, mutation load, fitness variation at the two levels (cell and cell group) and reproductive system (Michod, 1996, 1997; Michod \& Roze, 1999; Roze \& Michod, 2000). Under what conditions can evolution select for genetic modifiers of development, so as to increase the opportunity for between-group change, restrict the opportunity for within-group change and facilitate an evolutionary transition to multicellular individuals?

To understand the conditions under which an evolutionary transition occurs, we posit a modifier locus that modifies the biological processes described above (e.g. development, reproductive system, within-organism mutation and selection, and cell-cell interactions such as cooperation). Unlike the classical use of modifier models, say in the evolution of dominance and recombination, the modifiers studied in the present paper are not neutral. Instead, they have direct effects on fitness at the cell and organism level by changing the parameters of withinorganism change. By moulding the ways in which the levels interact so as to reduce conflict among cells, for example by segregating a germ line early or by policing the selfish tendencies of cells, the modifiers construct the first true emergent organism-level functions.

The modifier allele can affect virtually any aspect of the model, however, we have focused on three kinds of modifiers. A germ line modifier affects the way in which cells are chosen to be propagules and is assumed to sequester a group of cells that have a shorter development time and possibly a lower mutation rate than the soma, and, consequently, less selection at the cell level. A self-policing modifier causes cells in the group to spend time and energy monitoring other cells and reducing the advantages of defection, possibly at some cost to the group. An apoptotic modifier is more direct and is expressed by the mutant renegade cells themselves and lowers the rate of proliferation (or probability of survival) of mutated cells. When these modifiers of development and within-organism change increase in the population, the level of cooperation increases as does the heritability of fitness at the group level.

Figure 3 considers the evolution of a germ line modifier. As the modifier evolves, the average heritable fitness of the group

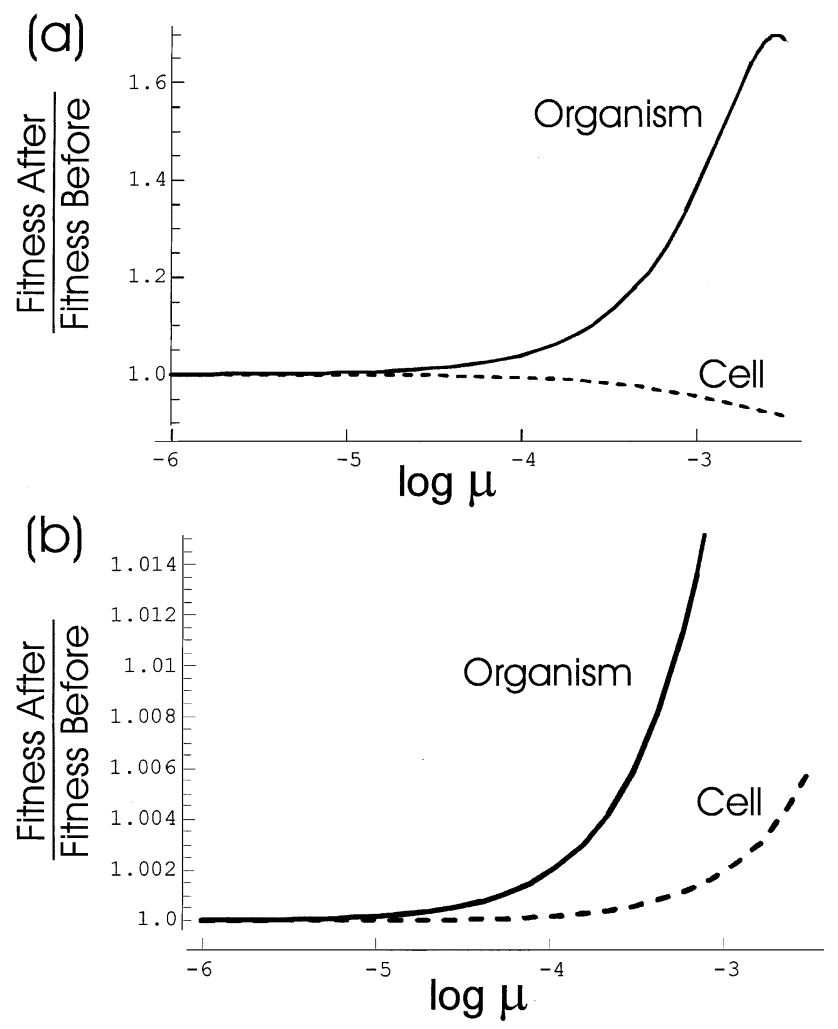

Fig. 3 Effect of evolutionary transition on fitness. The effect of an evolutionary transition on the heritability of fitness at the group and the cell level is shown as a function of the deleterious mutation rate for the case of (a) cell-cell altruism (selfish mutations) and (b) cell synergism (uniformly deleterious mutations). In both cases, the basic effect of modifier evolution is to increase the relative heritability of fitness at the group level compared to the cell level. Calculation of average organism fitness and cell fitness and construction of the figure is explained in Section 6 of Michod \& Roze (1999). 
increases, while the average fitness of the cells decreases. Both these effects increase with the mutation rate. When cooperation is beneficial at both levels, mutations are deleterious at both levels, and one may think that there is no conflict between the two levels of selection. However, as the modifiers evolve during the transition to multicellularity, fitness at the group level increases more than at the cell level as shown in Fig. 3(b).

Why do groups fare better than cells after the evolution of conflict modifiers that reduce the effective mutation rate? Modifiers evolve in this case by virtue of increasing the heritability of fitness in the more fit non-mutant (cooperative) subpopulation (Michod \& Roze, 1999). When cooperation is beneficial at both levels, on average both cells and cell groups are fitter after the transition, because the modifier decreases the effective mutation rate and mutation is deleterious at both levels. However, cell groups benefit twice from the lower mutation rate, because of their much larger size and enhanced functionality. To put the matter another way, when cooperation is beneficial at both levels, cell fitness may not be directly increased by mutation; however, relative to cell groups, cell fitness is increased, because groups are harmed more by mutation than are cells.

\section{Discussion and overview}

The theory reviewed here was originally developed for heuristic reasons, however, the basic variables and parameters are measurable and are in the process of being studied in different systems. For example, the theory has recently been applied (Blackstone \& Ellison, 2000) to the origin of basic developmental plans in multicellular animals in the late preCambrian some 600 million years ago (Davidson et al., 1995; Ransick et al., 1996). Davidson et al. propose certain features of early metazoans, including small size, a small and fixed number of cell divisions in early development, and specification of cell fates prior to cell movement. These features imply constraints on certain parameters of our model, specifically $t$ (the time available for cell division) and $b$ (the benefit to cells of not cooperating in terms of their rate of replication) (Blackstone \& Ellison, 2000). Such constraints clearly enhance between-cell cooperation and allow multicellularity to evolve more easily. Nevertheless, these constraints were circumvented by the evolution of set-aside cells, that is, undifferentiated cells that retain indefinite division potential. Our theory predicts that the evolution of set-aside cells must be accompanied by new features (new conflict mediators) which mediate cell-cell competition, and comparative data support this prediction (Ransick et al., 1996): the evolution of set-aside cells in metazoans was accompanied by the evolution of the sequestration of the germ line.

A corollary of our hypothesis is that having a germ line becomes more and more advantageous as organisms increase in size, since the frequency of mutants increases with development time and the number of cell divisions. A positive association of the occurrence of a germ line with organism size is also predicted by an alternative hypothesis based on division of labour (Bell, 1985). This hypothesis states that the organism has a greater fitness when some cells specialize in reproduction (the germ cells) and other cells specialize in other functions (the somatic cells), because each task can be performed more efficiently (Koufopanou, 1994). Furthermore, division of labour is assumed to be more fruitful in a big group than in a small one. According to both hypotheses, big organisms should be more likely to have a germ line. However, this conclusion need not be valid across taxa, because organisms from different taxa are subject to different constraints. For example, we expect that organisms from different taxa should differ in their susceptibility to selfish mutants. In plants, for example, selfish mutants do not have much opportunity to spread within the organism, because of the mechanical constraint of the rigid cell wall, whereas in animals cell mobility increases the risk of proliferation of selfish cells. Therefore, having a germ line could be more advantageous for a small animal than for a large plant. Comparisons between closely related species are useful, because these species may be subject to similar constraints. The Volvocales, for example, illustrate the association of larger size with earlier germ-soma differentiation (Bell, 1985), in agreement with the division of labour and conflict mediation hypotheses.

What happens during an evolutionary transition to a new higher-level unit of individuality, in this case the multicellular organism? Our theory assumes that the march towards multicellularity is fuelled by the advantages of cooperation and large size. Cooperation increases the fitness of the new higher-level unit, and, in this way, cooperation may create new levels of selection. However, the evolution of cooperation sets the stage for conflict, represented here by the increase of deleterious mutants within the emerging organism that tilt the balance of selection in favour of the lower level, cells in our case. The evolution of modifiers restricting the opportunity for selection among cells is the first higher-level function at the organism level. Before the evolution of a means to reduce conflict between levels of selection, the evolution of new group adaptations (such as the underlying traits leading to increased cooperation among cells) is frustrated by deleterious mutations. Individuality requires more than just cooperation among a group of genetically related cells, whether the cooperation is altruistic or synergistic; individuality depends upon the emergence of higher level functions that restrict the opportunity for conflict within and ensure the continued cooperation of the lower level units. Conflict leads - through the evolution of adaptations that reduce it - to greater individuality and harmony for the organism.

\section{Acknowledgements}

We thank Aurora Nedelcu for her helpful comments and criticisms. We also appreciate the comments of two anonymous reviewers and the editor.

\section{References}

BELL, G. 1985. The origin and early evolution of germ cells as illustrated by the Volvocales. In: Halvorson, H. O. and Monroy, A. (eds) The Origin and Evolution of Sex, pp. 221-256. Alan R. Liss, New York. BELL, G. AND KOUFOPANOU, v. 1991. The architecture of the life cycle in small organisms. Phil. Trans. R. Soc. B, 332, 81-89. 
BLACKSTONE, N. W. 1995. A units-of-evolution perspective on the endosymbiont theory of the origin of the mitochondrion. Evolution, 49, 785-796.

BLACKSTONE, N. W. AND Ellison, A. M. 2000. Maximal indirect development, set-aside cells, and levels of selection. J. Exp Zool. (Mol. Dev. Evol.), 288, 99-104.

BLACKSTONE, N. W. AND GREEN, D. R. 1999. The evolution of a mechanism of cell suicide. BioEssays, 21, 84-88.

BOERLIJST, M. C. AND HOGEWEG, P. 1991. Spiral wave structure in prebiotic evolution: Hypercycles stable against parasites. Physica D, 48, 17-28.

BoraAs, M. E., SEALE, D. B. AND BOXHORN, J. E. 1998. Phagotrophy by a flagellate selects for colonial prey: a possible origin of multicellularity. Evol. Ecol., 12, 153-164.

BUSS, L. W. 1987. The Evolution of Individuality. Princeton University, Princeton, NJ.

CAVALIER-SMITH, T. 1987. Eukaryotes with no mitochondria. Nature, 326, 332-333.

DAVIdSON, E. H., PETERSON, K. J. AND CAMERON, R. A. 1995. Origin of bilateral body plans: evolution of developmental regulatory mechanisms. Science, 270, 1319-1325.

EIGEN, M. AND schuster, P. 1979. The Hypercycle, A Principle of Natural Self-Organization. Springer-Verlag, Berlin.

FEWELL, J. AND PAGE, R. E. JR. 1999. The emergence of division of labour in forced associations of normally solitary ant queens. Evol. Ecol. Res., 1, 1-12.

FRANK, s. A. 1995. The origin of synergistic symbiosis. J. Theor. Biol., 176, 403-410.

FRANK, S. A. 1997. Models of symbiosis. Am. Nat., 150, S80-S99.

GREY, D., HUTSON, V. AND SZATHMáRY, E. 1995. A re-examination of the stochastic corrector model. Proc. R. Soc. B., 262, 29.

GUERRERo, R. 1991. Predation as prerequisite to organelle origin: Daptobacter as example. In: Margulis, L. and Fester, R. (eds) Symbiosis as a Source of Evolutionary Innovation: Speciation and Morphogenesis. MIT Press, Cambridge, MA.

KIRK, D. L. 1997. Volvox. Molecular Genetic Origins of Multicellularity and Cellular Differentiation. Cambridge University Press, New York.

Koufopanou, v. 1994. The evolution of soma in the Volvocales. Am. Nat., 143, 907-931.

KROEMER, G. 1997. Mitochondrial implication in apoptosis: towards an endosymbiont hypothesis of apoptosis evolution. Cell Death and Differentiation. 443-456.

LAw, R. 1991. The symbiotic phenotype: origins and evolution. In: Margulis, L. and Fester, R. (eds) Symbiosis as a Source of Evolutionary Innovation, pp. 57-71. MIT Press, Cambridge, MA.

LOPEZ-GARCIA, P. AND MOREIRA, D. 1999. Metabolic symbiosis at the origin of eukaryotes. Trends Biochem. Sci., 24, 88-93.

margulis, L. 1981. Symbiosis in Cell Evolution. W. H. Freeman, San Francisco.

MARgulis, L. 1993. Symbiosis in Cell Evolution, Microbial Communities in the Archean and Proterozoic Eons, 2nd edn. W. H. Freeman, New York.
MARTIN, W. F. AND MÜLLER, M. 1998. The hydrogen hypothesis for the first eukaryote. Nature, 392, 37-41.

MAYNARD SMITH, J. 1979. Hypercycles and the origin of life. Nature, 280, 445-446.

MAYNARD SMITH, J. 1998. Evolutionary Genetics, 2nd edn. Oxford University Press, Oxford.

MAYNARD SMITH, J. AND SZATHMÁRY, E. 1995. The Major Transitions in Evolution. W. H. Freeman, San Francisco.

MICHOD, R. E. 1983. Population biology of the first replicators: on the origin of the genotype, phenotype and organism. Am. Zool., 23, 5-14.

MICHOD, R. E. 1996. Cooperation and conflict in the evolution of individuality. II. Conflict mediation. Proc. R. Soc. B., 263, 813-822.

MICHOD, R. E. 1997. Cooperation and conflict in the evolution of individuality. I. Multi-level selection of the organism. Am. Nat., 149, 607-645.

MICHOD, R. E. 1999. Darwinian Dynamics, Evolutionary Transitions in Fitness and Individuality. Princeton University Press, Princeton, NJ.

Michod, R. E. AND ROZE, D. 1997. Transitions in individuality. Proc. $R$. Soc. B., 264, 853-857.

MICHOD, R. E. AND ROZE, D. 1999. Cooperation and conflict in the evolution of individuality. III. Transitions in the unit of fitness. In: Nehaniv, C. L. (ed.) Mathematical and Computational Biology: Computational Morphogenesis, Hierarchical Complexity, and Digital Evolution, vol. 26, pp. 47-92. American Mathematical Society, Providence, RI.

MICHOD, R. E. AND ROZE, D. 2000. Reproductive mode and the origin of multicellularity. Selection, 1, 133-145.

MICHOD, R. E. AND SANDERSON, M. J. 1985. Behavioural structure and the evolution of social behaviour. In: Greenwood, J. J. and Slatkin, M. (eds) Evolution - Essays in Honour of John Maynard Smith, pp. 95-104. Cambridge University Press, Cambridge.

MOREIRA, D. AND LOPEZ-GARCIA, P. 1998. Symbiosis between methanogenic archaea and delta-proteobacteria as the origin of eukaryotes: the syntrophic hypothesis. J. Mol. Evol., 47, 517-530.

QUELLER, D. C. 1994. Genetic relatedness in viscous populations. Evol. Ecol., 8, 70-73.

QUEller, D. C. 1997. Cooperators since life began. Q. Rev. Biol., 72, 184-188.

RANSICK, A., CAMERON, R. A. AND DAVIDSON, E. H. 1996. Postembryonic segregation of the germ line in sea urchins in relation to indirect development. Proc. Natl. Acad. Sci. U.S.A., 93, 6759-6763.

ROZE, D. AND MICHOD, R. E. 2000. Mutation load, multi-level selection and the evolution of reproductive mode. Submitted ms.

SAGAN, L. 1967. On the origin of mitosing cells. J. Theor. Bio., 14, 225275.

TAYLOR, P. D. 1992. Altruism in viscous populations - an inclusive fitness model. Evol. Biol., 6, 352-356.

WILson, E. O. 1975. Sociobiology: The New Synthesis. Belknap Press, Cambridge, MA.

Wright, R. 2000. Nonzero: the Logic of Human Destiny. Pantheon Books, New York.

Wright, s. 1969. Evolution and the Genetics of Populations, vol. 2. The Theory of Gene Frequencies. University of Chicago Press, Chicago. 